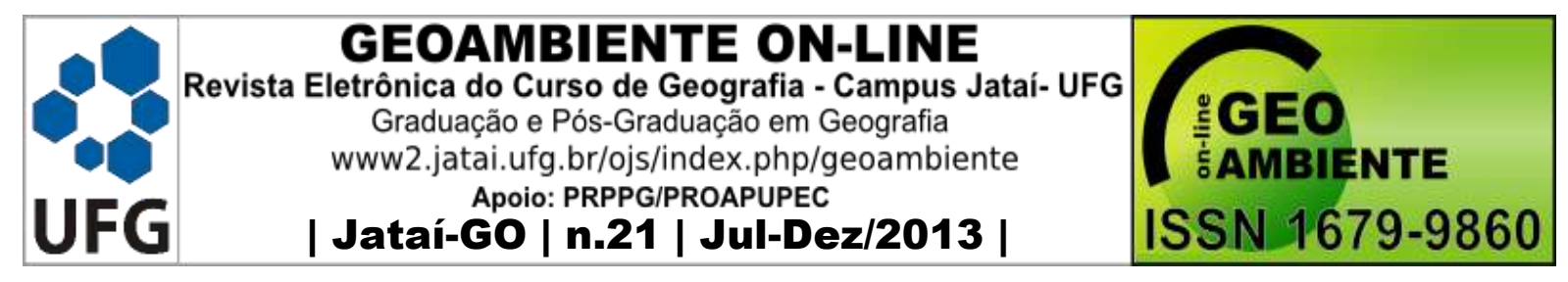

\title{
ANÁLISE DAS VARIAÇÕES TERMO-HIGROMÉTRICAS E DE CONFORTO TÉRMICO NA CIDADE DE BIRIGUI-SP: SUBSIDIOS AO PLANEJAMENTO AMBIENTAL URBANO
}

Márcio Fernando Gomes'; Deise Regina Elias Queiróz

(1- Universidade Estadual de Maringá, Doutorando em Geografia; UNIESP/FABI, Docente do Curso de Geografia, marcioparker@ hotmail.com. 2 - Universidade Estadual de Maringá,

Professora Doutora, deisequeiroz@ig.com.br)

\section{RESUMO}

O crescente processo de urbanização tem trazido inúmeras modificações no ambiente natural. Em decorrência desse processo vem surgindo nos últimos anos uma série de problemas socioambientais que afetam diretamente a qualidade de vida dos citadinos. O clima configurase como um dos principais elementos influenciados pelo desenfreado processo de urbanização. O aumento de temperatura, a redução na umidade relativa do ar e o desconforto térmico são exemplos das modificações do clima nas áreas urbanas. Diante deste contexto, o presente trabalho realizou o estudo das variações termo-higrométricas e do conforto térmico na cidade de Birigui através do emprego de técnicas de geoprocessamento. Para realização da pesquisa foram coletados dados em campo, utilizado dois termo-higrômetros digitais, em dois transectos pré-estabelecidos. As variações termo-higrométricas foram representadas em mapas de isolinhas (isoígras) com o auxílio do software Surfer 8 e o interpolador de krigagem ordinária. Os resultados demonstraram que há redução da umidade relativa do ar, aumento de temperatura e desconforto térmico nas áreas centrais quando comparado com a periferia da cidade.

Palavras-Chave: Clima Urbano; Qualidade Ambiental; Ilhas de Calor.

\section{ABSTRACT}

ANALYSIS OF CHANGES HYGROMETRIC-TERM AND THERMAL COMFORT

IN THE CITY OF BIRIGUI-SP: GRANTS TO URBAN ENVIRONMENTAL PLANNING

\footnotetext{
Artigo recebido para publicação em 16 de Setembro de 2013 Artigo aprovado para publicação em 24 de Dezembro de 2013
} 


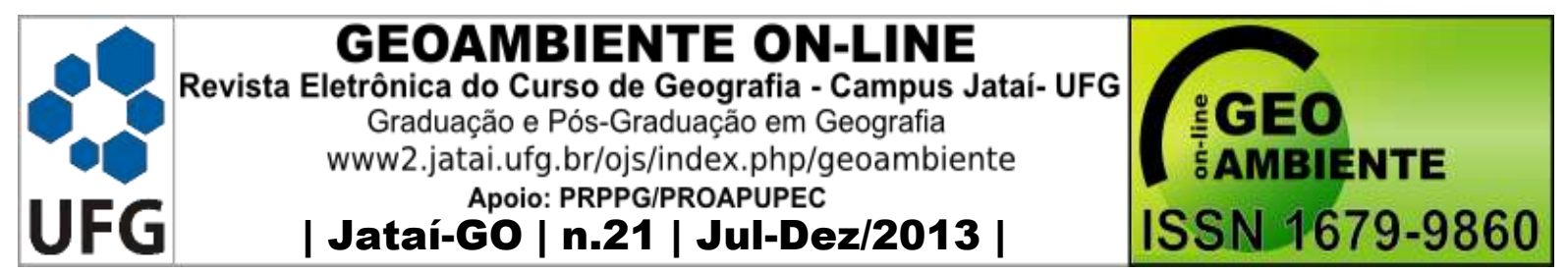

The growing process of urbanization has brought many changes in the natural environment. Due to this process has been emerging in recent years a number of environmental issues that directly affect the quality of life of city dwellers. The climate is characterized as one of the major elements influenced by rampant urbanization. The temperature increase, the reduction in relative humidity and thermal discomfort are examples of climate change in urban areas. Given this context, the present work the study of thermo- hygrometric variations and thermal comfort in the city of Birigüi by employing GIS techniques. To conduct the survey field data, used two digital thermo- hygrometers, two pre-established transects were collected. The thermo- hygrometric variations were represented in contour maps (isoígras ) using the Surfer 8 software interpolator and ordinary kriging. The results showed that there is decrease in relative humidity, temperature rise and thermal discomfort in the central areas compared to the suburbs.

Key words: Urban Climate , Environmental Quality , Heat Islands

\section{RESUMEN}

\section{ANÁLISIS DE LOS CAMBIOS TERMOHIGROMÉTRICO Y CONFORT TÉRMICO EN LA CIUDAD DE BIRIGUI -SP: SUBVENCIONES PARA UNA PLANIFICACIÓN AMBIENTAL URBANA}

El creciente proceso de urbanización ha traído muchos cambios en el entorno natural. Debido a este proceso ha ido surgiendo en los últimos años una serie de problemas ambientales que afectan directamente la calidad de vida de los habitantes de la ciudad. El clima se caracteriza como uno de los principales elementos de la influencia de la urbanización desenfrenada. El aumento de la temperatura, la reducción de la humedad relativa y la incomodidad térmica son ejemplos del cambio climático en las zonas urbanas. Dado este contexto, el presente trabajo el estudio de las variaciones termohigrométricas y confort térmico en la ciudad de Birigüi mediante el empleo de técnicas de SIG. Para llevar a cabo los datos de campo encuesta, que se utiliza dos termo- higrómetros digitales, se recogieron dos transectos preestablecidos. Las variaciones termohigrométricas se representaron en mapas de contorno (isoígras) utilizando el software de interpolación Surfer 8 y kriging ordinario. Los resultados mostraron que hay disminución de la humedad relativa, aumento de la temperatura y la incomodidad térmica en las áreas centrales en comparación con los suburbios.

Palabras clave: Urban clima, la calidad del medio ambiente, las islas de calor 


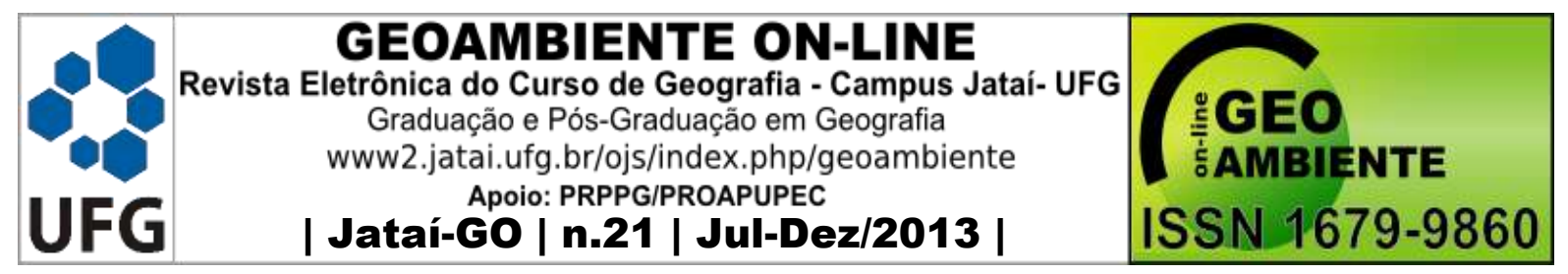

\section{INTRODUÇÃO}

A partir da segunda metade do século XX o município de Birigui, assim como a maioria das cidades brasileiras, apresentaram um intenso e acelerado processo de urbanização. Aliados a esta dinâmica surgem inúmeros problemas de ordem sócio-ambiental que afetam diretamente a qualidade de vida da população.

De acordo com Troppmair (1987) o sistema urbano apresenta condições geoecológicas específicas que alteram profundamente as condições naturais, com reflexos decisivos para os seres humanos. "As pressões exercidas pela concentração de população e de atividades geradas pela urbanização e industrialização concorrem para acentuar as modificações do meio ambiente, com comprometimento da qualidade de vida" (MONTEIRO, 1987).

Entre os impactos ambientais do meio urbano que afetam a qualidade de vida destacam-se principalmente os associados à contaminação de mananciais, as inundações urbanas, os deslizamentos de terra, a retirada da cobertura vegetal e ausência de áreas verdes, a alteração das condições climáticas, como a poluição atmosférica e formação de ilhas de calor.

Diante deste contexto, o presente trabalho teve como objetivo estudar as variações de temperatura, umidade relativa do ar e conforto térmico na área urbana de Birigui através do emprego de técnicas de geoprocessamento.

\section{CLIMA URBANO: TEMPERATURA, UMIDADE RELATIVA DO AR E CONFORTO TÉRMICO}

O crescente processo de urbanização tem trazido inúmeras modificações no ambiente. A transformação e alteração do ambiente natural se dão pela humanização dessa natureza e alcançam "maior expressão nos espaços ocupados pelas cidades, criando um ambiente artificial” (LOMBARDO, 1985, p.17).

Em decorrência desse processo vem surgindo nos últimos anos uma série de problemas socioambientais, que afetam diretamente a qualidade de vida dos citadinos.

O clima configura-se como um dos principais elementos influenciados pelo desenfreado processo de urbanização. O clima urbano "é derivado da alteração na paisagem natural e da sua substituição por um ambiente construído, palco de intensas atividades humanas" (MENDONÇA, 2000, p.168). 


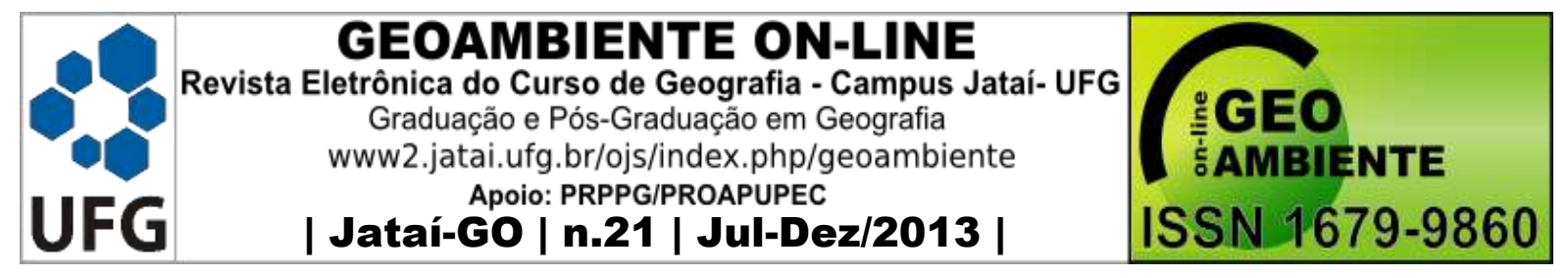

Segundo Mendonça (2000) as mudanças climáticas mais observadas no ambiente urbano estão às relacionadas à temperatura, a umidade relativa do ar e aos ventos; e nas cidades tropicais, a precipitação. Lombardo (1985) acrescenta que a temperatura e a concentração de poluentes são as expressões mais significativas da alteração climática nas cidades e podem ser usadas para indicar a degradação ambiental destes ambientes.

Em decorrência das alterações de muitos parâmetros climáticos na área urbana, inúmeros estudos foram desenvolvidos nas últimas décadas a fim de compreender esta nova conjuntura. Entre eles sobressaem-se principalmente os ligados à elevação da temperatura na área urbana e a formação de ilhas de calor (TARIFA, 1977; OKE 1978; LOMBARDO, 1985; PITTON, 1997; AMORIM, 2000; MENDONÇA, 2000 e 2003).

As áreas urbanas tendem a apresentar temperaturas mais elevadas que o entorno, propiciando muitas vezes o surgimento de uma circulação específica na cidade; esse fenômeno descrito recebe o nome de ilha de calor (LOMBARDO, 1985).

Segundo Oke (1978 apud LOMBARDO, 1985) as ilhas de calor são resultado das modificações dos parâmetros da superfície e da atmosfera pela urbanização. A elevação da temperatura sobre as cidades e a conseqüente formação de ilhas de calor ocorre devida à redução da evaporação, ao aumento da rugosidade e pelas propriedades térmicas das áreas construídas (LOMBARDO, 1985).

A baixa densidade de áreas verdes e a impermeabilização do solo na cidade diminuem a taxa de evaporação, fator que contribui para o aumento de temperatura. A produção de energia antropogênica, através da emissão de calor pelas indústrias, o movimento dos automóveis e o aumento de construções são fatores que contribuem para elevação de temperatura na cidade (ERIKSEN, 1978 apud LOMBARDO, 1985).

As pesquisas têm demonstrado que a distribuição espacial da temperatura e a formação das ilhas de calor apresentam uma configuração espacial muito similar, de modo geral, as temperaturas mais elevadas são registradas no centro da cidade, passando por uma diminuição progressiva conforme se desloca para periferia (figura 1).

Apesar de grande parte das pesquisas ilustrarem este resultado, cabe destacar que as variações térmicas e a intensidade da ilha de calor em uma cidade variam de acordo com características geoecológicas, como uso e ocupação do solo e densidade de áreas verdes, densidade populacional e tamanho da cidade. 


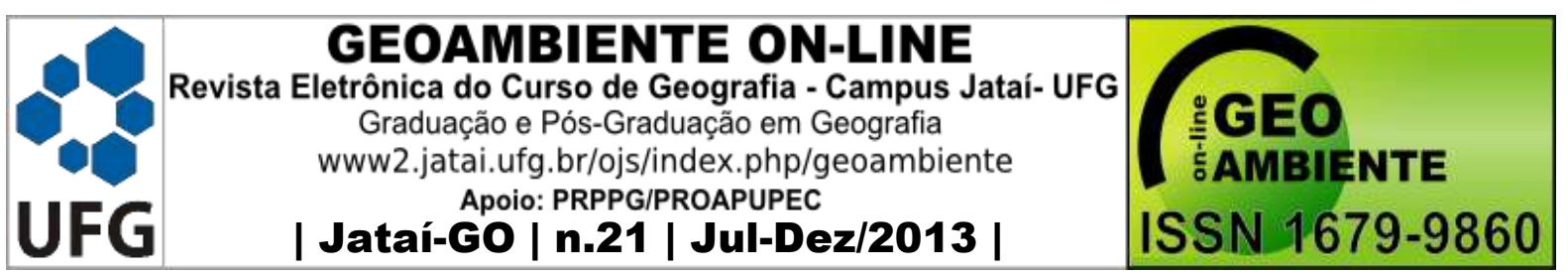

Figura 1: Representação esquemática da Ilha de Calor Urbana

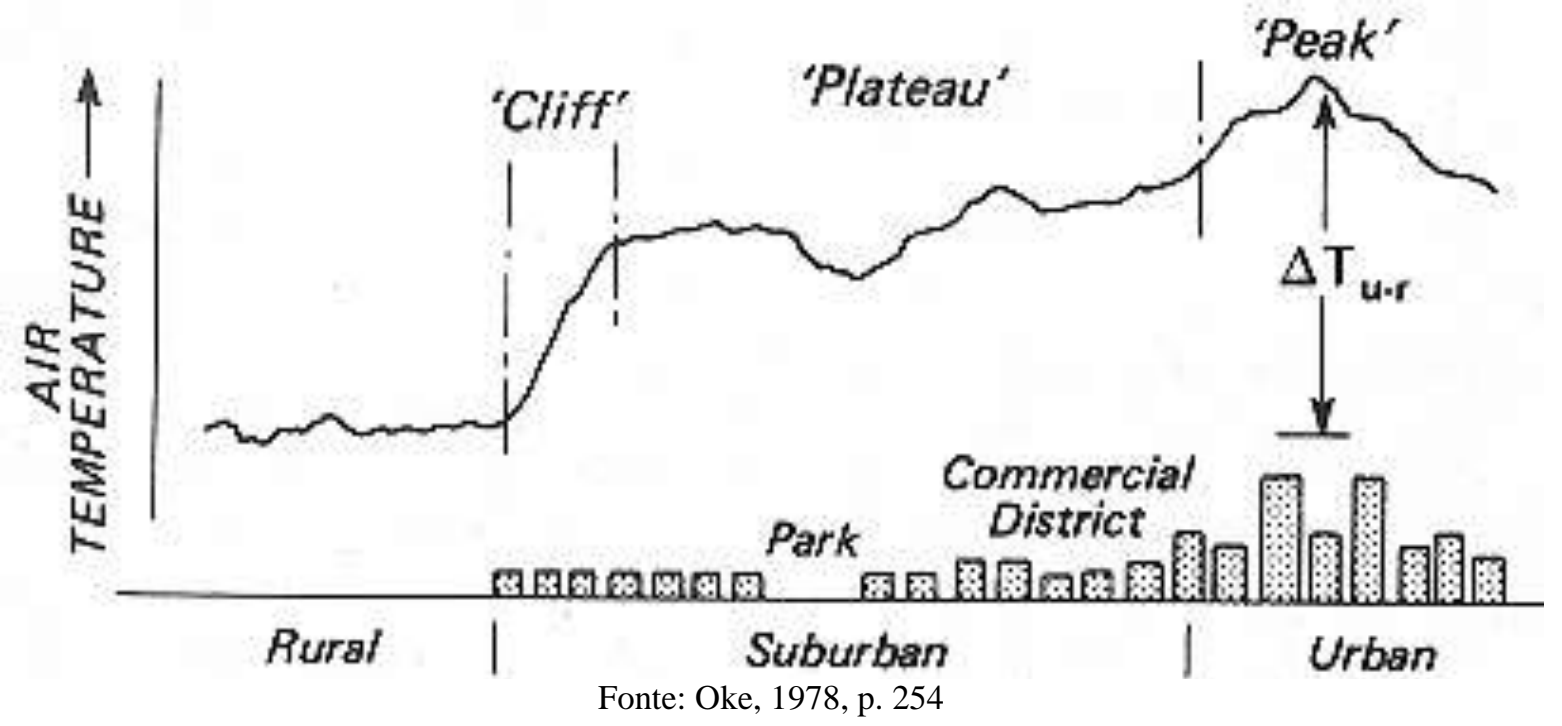

As ilhas de calor e o gradiente térmico possuem maior expressão nas grandes cidades. Em estudo realizado em São Paulo, Lombardo (1985) encontrou diferenças térmicas de até 10 ${ }^{\circ} \mathrm{C}$ no interior da cidade. Nos últimos anos as cidades médias e pequenas também começam a atestar, em nível inferior, estas situações.

Assim como a temperatura, a umidade relativa do ar experimenta modificações significativas nas áreas urbanas. As impermeabilizações do solo, com superfícies edificadas e pavimentadas fazem com que a evacuação da precipitação seja muito rápida, o que associado às poucas superfícies de solo natural e vegetação, atuam na redução da evapotranspiração e umidade relativa do ar (GARCIA, 1999).

Lombardo (1985) destaca que há uma relação estreita entre o aumento de temperatura na cidade e a diminuição da umidade relativa do ar. A umidade relativa do ar apresenta um padrão espacial inverso ao da temperatura, ou seja, registra menor intensidade nas áreas centrais e aumenta gradativamente em relação aos limites da cidade.

Em virtude do aumento de temperatura e queda da umidade relativa do ar as cidades tendem a apresentar quadros de desconforto térmico. Nos grandes núcleos urbanos o elevado número de edificações e acumulação de calor causa um stress térmico que em clima tropical colaboram para ocorrência de desconforto térmico e ultrapassa limites de tolerância dos habitantes (LOMBARDO, 1985).

Ribeiro e Silva (2006) afirmam que uma das conseqüências das mudanças do clima na cidade é seu impacto no conforto térmico. O processo de urbanização modifica o clima local 


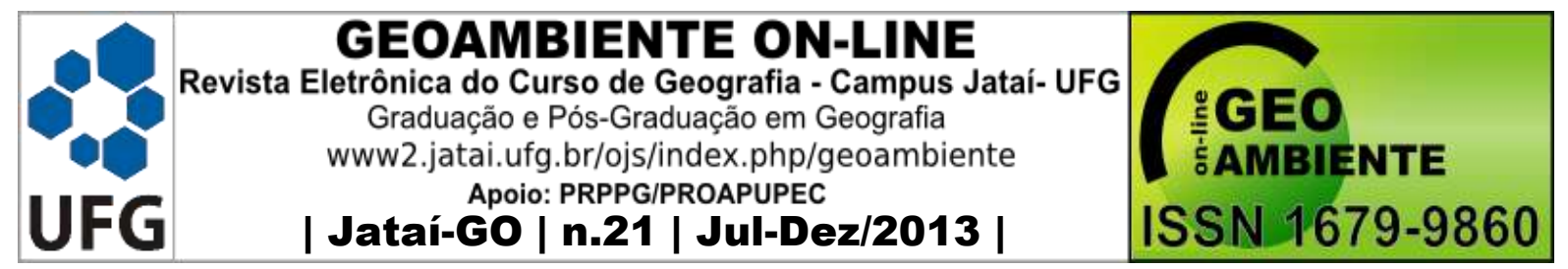

de modo que as diferenciações na composição dos ambientes intra-urbanos criam condições ao conforto ou desconforto climático de seus habitantes. De acordo com García (1996) conforto térmico é o "conjunto de condições em que os mecanismos de autorregulação são mínimos" ou ainda "a zona delimitada por características térmicas em que o maior número de pessoas manifeste se sentir bem".

Em relação ao conforto térmico, Krüger (2002) afirma que essa definição "indica que a sensação de conforto depende tanto de aspectos físicos do ambiente (o ambiente térmico) como também de aspectos subjetivos (o estado mental)".

Para Vogt e Miller Chagas (1970 apud DUMKE, 2007, p. 132):

(...) o conforto térmico é uma sensação complexa que sofre influência de fatores de ordem física, fisiológica e psicológica [...]; do ponto de vista puramente térmico, as condições ambientais confortáveis são aquelas que permitem ao ser humano manter constante a temperatura do corpo sem adicionar, de forma perceptível, seus mecanismos termorreguladores.

A sensação de conforto térmico varia de uma pessoa para outra, pois as características fisiológicas são diferenciadas de individuo para individuo (BESANCENOT, 1997; MENDONÇA, 2001; DUMKE, 2007).

Cabe destacar que o homem é um animal homeotérmico e tem necessidade de manter constante a temperatura interna de seu organismo mesmo que as condições externas variem. A temperatura interna média da maioria das pessoas situa em torno de $37^{\circ} \mathrm{C}$, a ocorrência de variações acima de $1{ }^{\circ} \mathrm{C}$ e $2{ }^{\circ} \mathrm{C}$ por um tempo relativamente longo podem afetar seriamente o organismo humano, enquanto uma alteração na ordem de $4{ }^{\circ} \mathrm{C}$ poderá causar lesão permanente ou morte (RORIZ, 1987 apud DUMKE, 2007).

Os mecanismos de autorregulação atuam de acordo com as condições térmicas Dumke (2007, p. 133 - 134) destaca que:

Na presença de frio, os mecanismos termorreguladores são ativados visando evitar as perdas térmicas e aumentar a produção interna de calor: a vasoconstrição periférica faz com que a pele se resfrie para evitar perdas de calor por radiação $e$ convecção; o arrepio aquece a pele por atrito, ao mesmo tempo em que a maior rugosidade da pele evita perdas de calor por convecção; e o aumento do metabolismo entre 30 e $100 \%$ pode se manifestar pelo tremor dos músculos, produzindo um maior calor interno para compensar as perdas para o meio.(...)

(...) Na presença de calor, a vasodilatação periférica aumenta a temperatura da pele favorecendo a perda de calor por convecção e radiação; por meio da transpiração, a evaporação favorece as perdas de calor; $e$ a redução do metabolismo visa à diminuição da produção de calor no interior do organismo. 


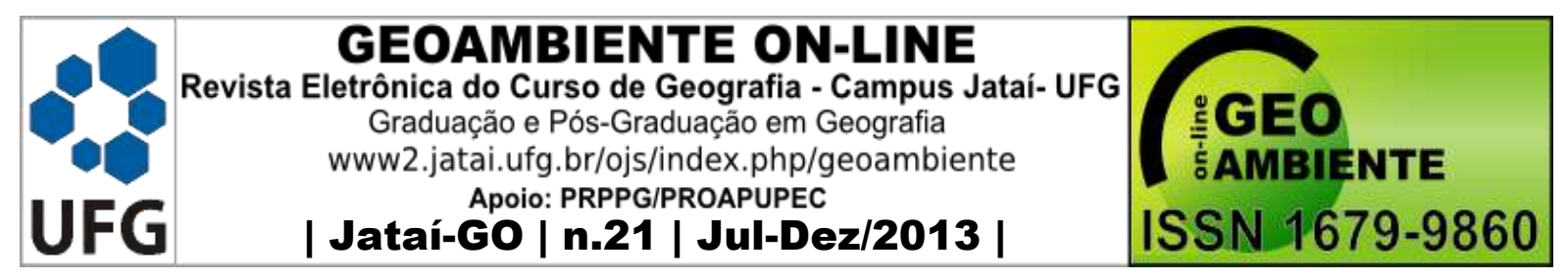

Em condições extremas, o organismo pode não ser capaz de responder às alterações e entrar em desequilíbrio. Segundo Mendonça (2001 apud DUMKE, 2007):

\begin{abstract}
Quando os fatores do ambiente atingem valores extremos, sob atuação de ondas de calor ou de frio, de ventos violentos ou de precipitações abundantes, por exemplo, então eles afetam a saúde humana. Assim a mortalidade aumenta durante as ondas de calor (sobretudo crianças e idosos), sendo cada vez mais marcada quando temperaturas elevadas se combinam com forte higrometria. [...] $O$ calor tem também efeitos menos espetaculares como as cãibras de calor ou as insolações que se degeneram às vezes em hipertermia.
\end{abstract}

Diante da importância das variações termo-higrométricas para saúde e qualidade de vida da população, vários estudos foram produzidos no intuito de identificar o estado ótimo de conforto térmico. Os resultados variam devido à diversidade de variáveis consideradas, métodos e localização dos estudos (DUMKE, 2007).

Diante deste contexto, o diagnóstico e mapeamento das variações termo-higrométricas contribuem para identificação das áreas com conforto/desconforto térmico e consequentemente para o planejamento ambiental urbano e a tomada de decisões. Neste sentido o presente trabalho apresenta um estudo das variações termo-higrométricas na cidade de Birigui-SP, enfocando a utilização da representação gráfica através das técnicas de geoprocessamento.

\title{
3. ÁREA DE ESTUDO
}

O município de Birigui está localizado na região noroeste do estado de São Paulo, entre as latitudes $21^{\circ} 03^{\prime} 32,89^{\prime \prime} \mathrm{S}$ e $21^{\circ} 28^{\prime} 01,53^{\prime \prime} \mathrm{S}$, e longitudes $50^{\circ} 14^{\prime} 29,01^{\prime \prime} \mathrm{W}$ e $50^{\circ} 27^{\prime}$ 57,29" W (Figura 2). Atualmente o espaço urbano de Birigui possui uma área de aproximadamente $28 \mathrm{~km}^{2}$ e conta com uma população de 105.481 habitantes (IBGE, 2010), o que representa uma densidade demográfica de $3767 \mathrm{~h} / \mathrm{km}^{2}$.

Segundo a classificação de Koppen (1995) o clima do município de Birigui é do tipo Aw, ou seja, tropical úmido, com invernos secos e chuvas máximas no verão. A temperatura média do mês mais frio é superior a $18^{\circ} \mathrm{C}$ e a precipitação média do mês mais seco inferior a $60 \mathrm{~mm}$. O clima se caracteriza por duas estações bem definidas: uma estação seca de tempo estável (outono-inverno) e outra quente e úmida com chuvas freqüentes e intensas (primavera - verão) (figura 3). A região sofre na maior parte do ano a atuação da massa de ar Tropical Atlântica responsável pela estabilidade no inverno e instabilidade no verão. No verão atua 


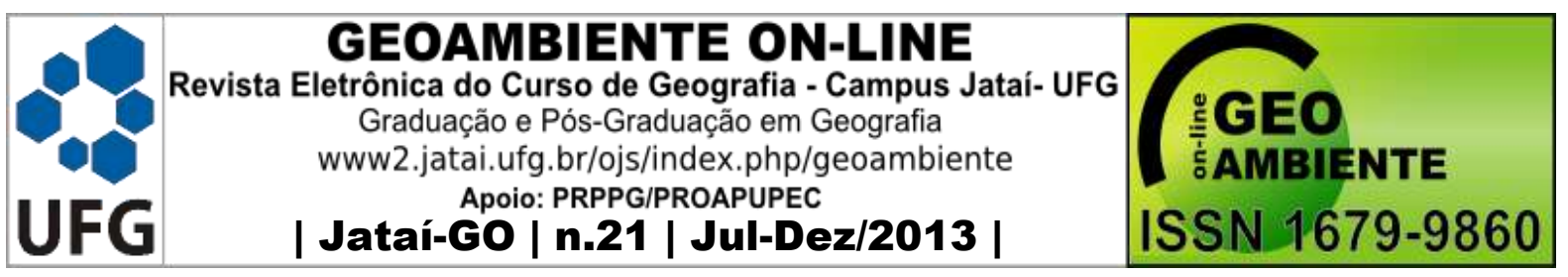

mais intensamente na região a massa de ar Tropical Continental e a massa de ar Equatorial e no inverno a massa de ar Polar Atlântica.

Figura 2: Localização Birigui - SP.

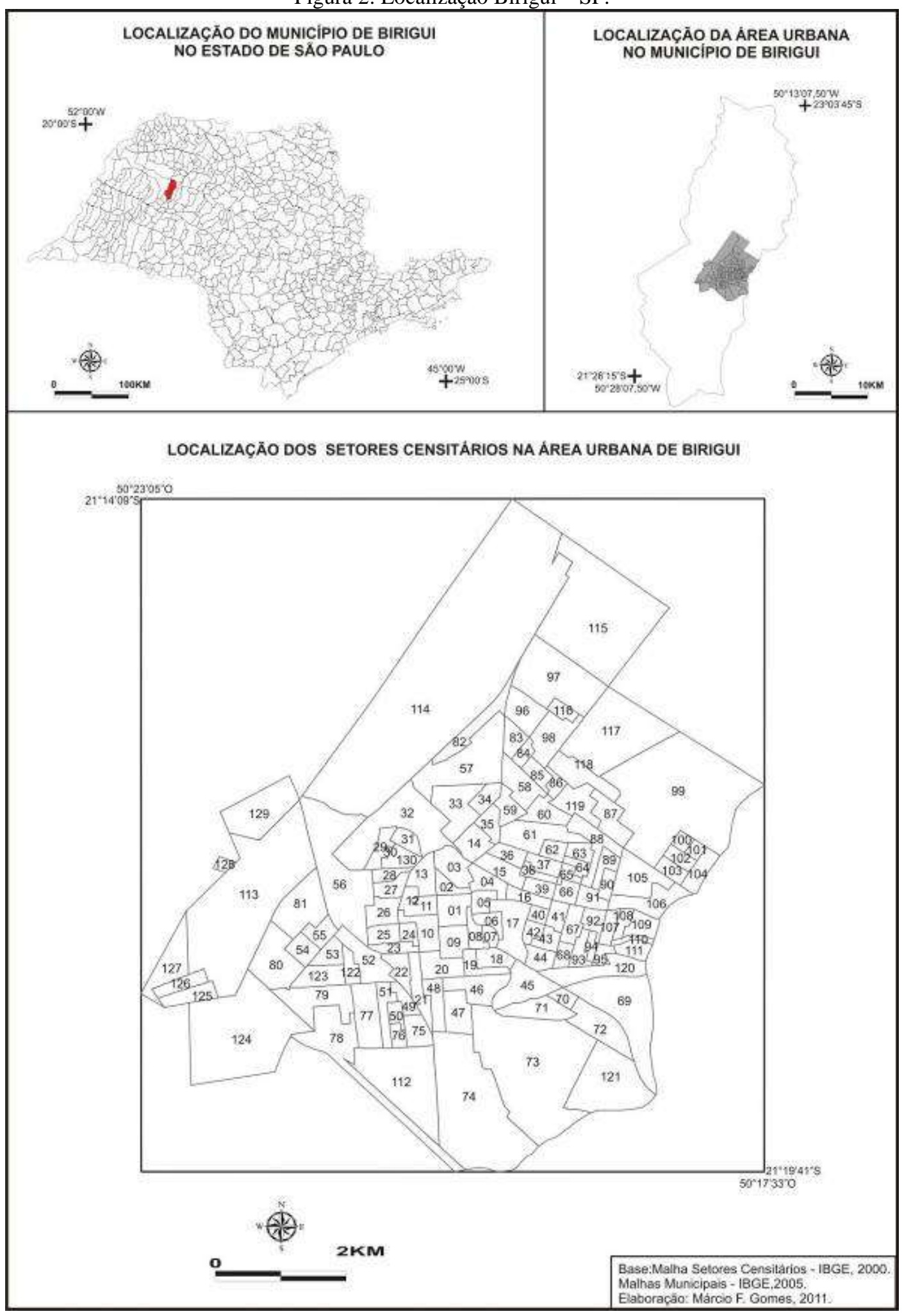




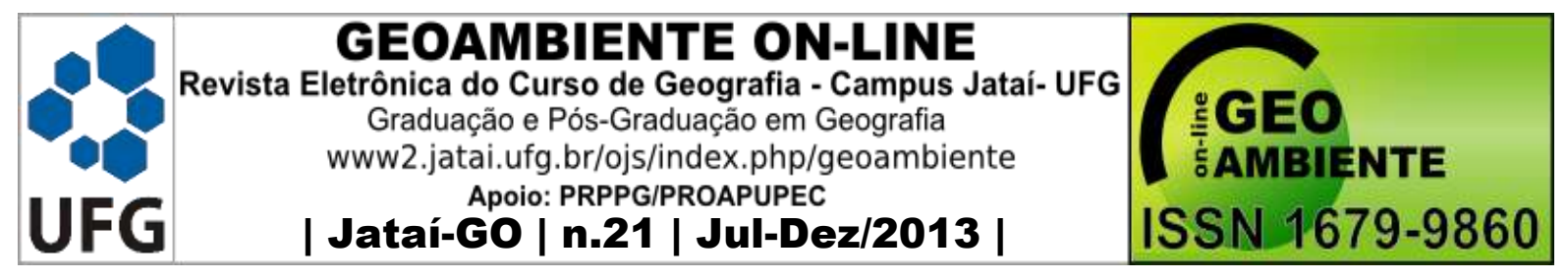

Figura 3: Climograma, Birigui-SP

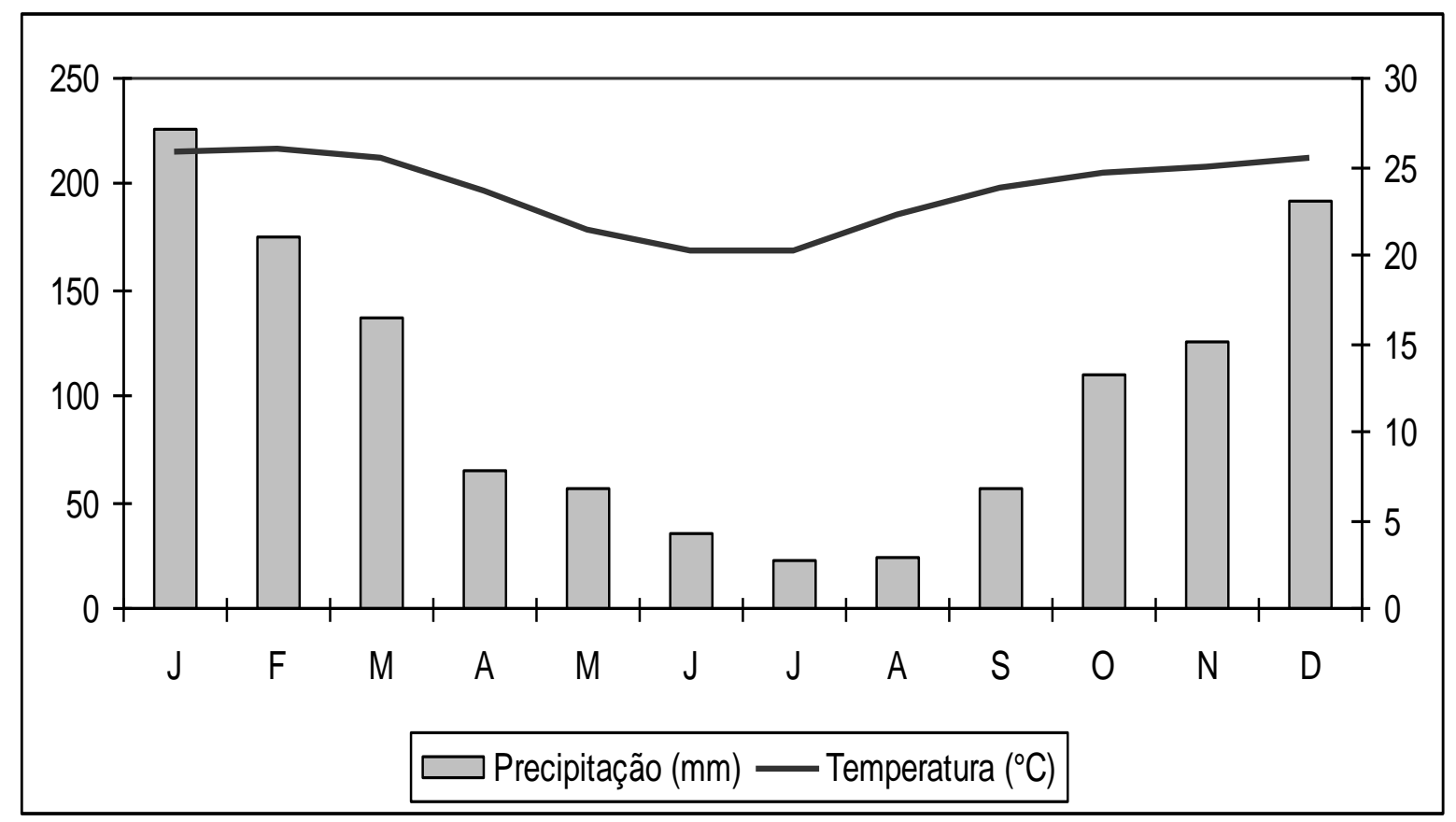

Fonte: CEPAGRI, 2010.

\section{PROCEDIMENTOS METODOLÓGICOS}

Para realização do diagnóstico das variações termo-higrométricas e do conforto térmico na área urbana de Birigui foram realizados trabalhos de campo, com mensurações da temperatura do ar e umidade relativa do ar em diversos pontos distribuídos pela cidade.

O levantamento dos dados meteorológicos foi realizado através de dois transectos préestabelecidos, um no sentido norte-sul com 13 pontos de coleta e um no sentido leste- oeste com 10 pontos de coleta (figura 4). O percurso foi realizado com automóvel em uma velocidade média de $25 \mathrm{~km} / \mathrm{h}$.

Para mensuração dos dados meteorológicos foi utilizado dois termo-higrômetros digitais HT-7002 da marca ICEL, que registram os valores da temperatura e umidade relativa do ar.

Os dados foram coletados as 15:00 horas, período de maior aquecimento diurno, em oito dias da estação de verão $(23,24,30$ e 31 de janeiro e 06, 07, 20 e 21 de fevereiro) do ano de 2010. Nesta pesquisa, no intuito de demonstrar o emprego de técnicas de geoprocessamento no estudo das variações de temperatura, umidade relativa do ar e conforto térmico na área urbana de Birigui, foi utilizado o episódio registrado em 23/01/2010. 


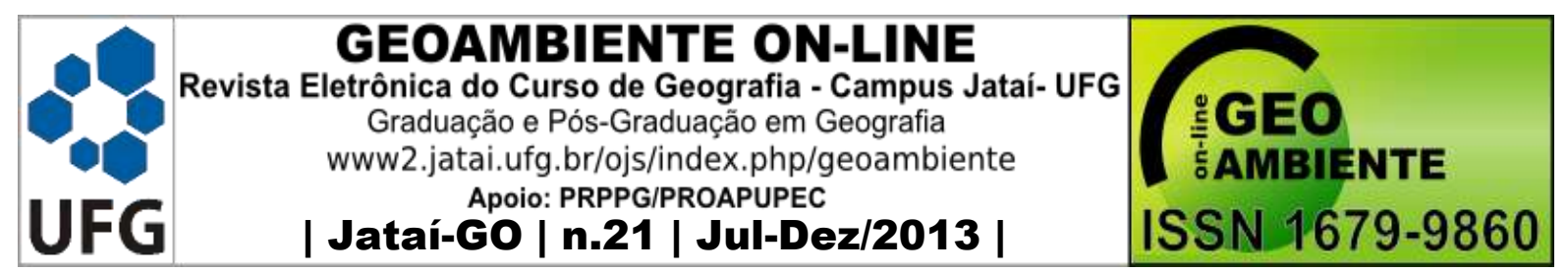

$\mathrm{Na}$ avaliação do conforto térmico foi utilizado o Diagrama do Conforto Humano apresentado pelo INMET (figura 5). Com base nos resultados, os setores censitários da cidade foram classificados em três classes: "Muito Quente"; "Necessário Vento para Conforto"; e "Área de Transição entre Muito Quente e Necessário Vento para Conforto".

Figura 4: Transectos e pontos de coleta de dados

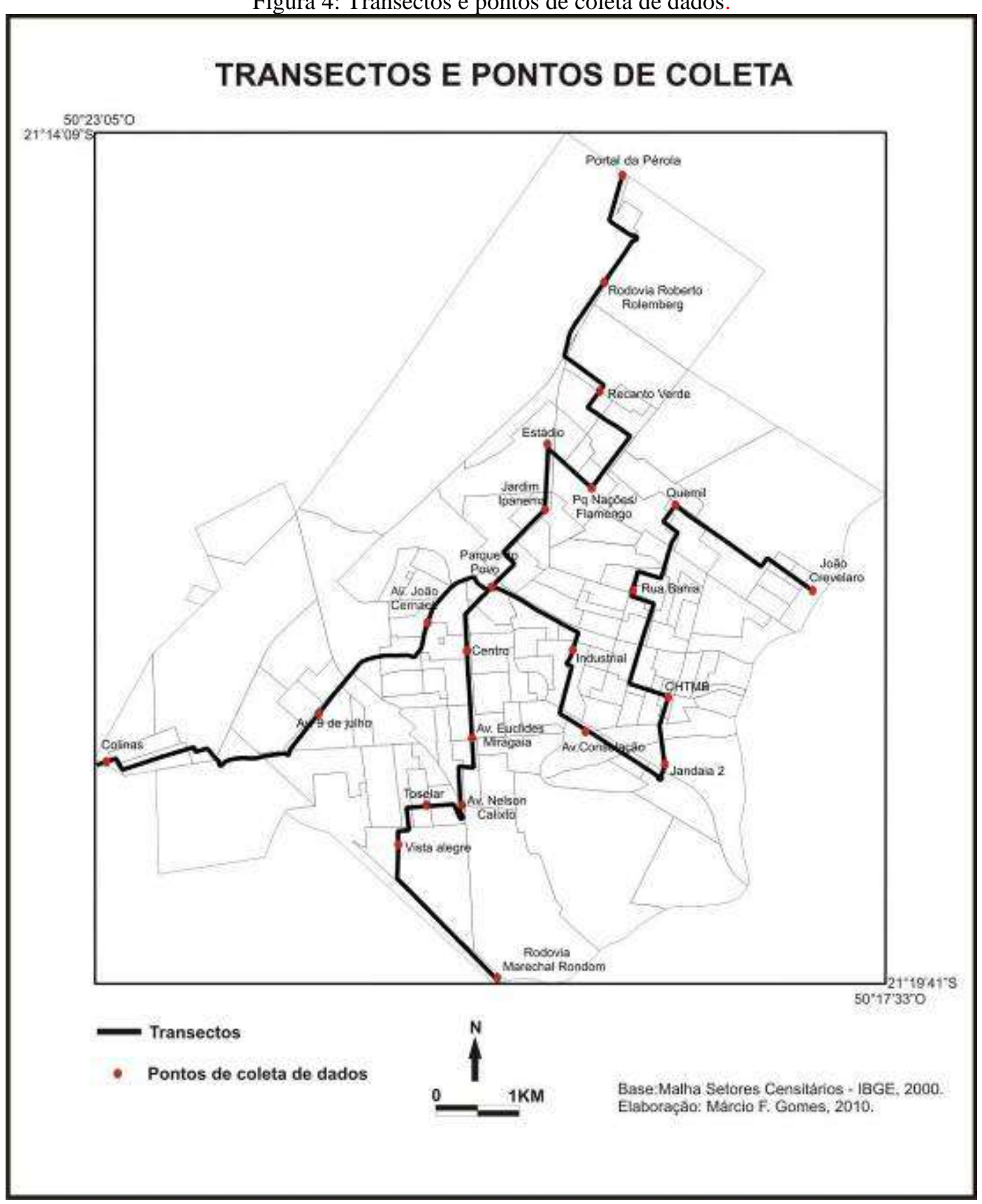




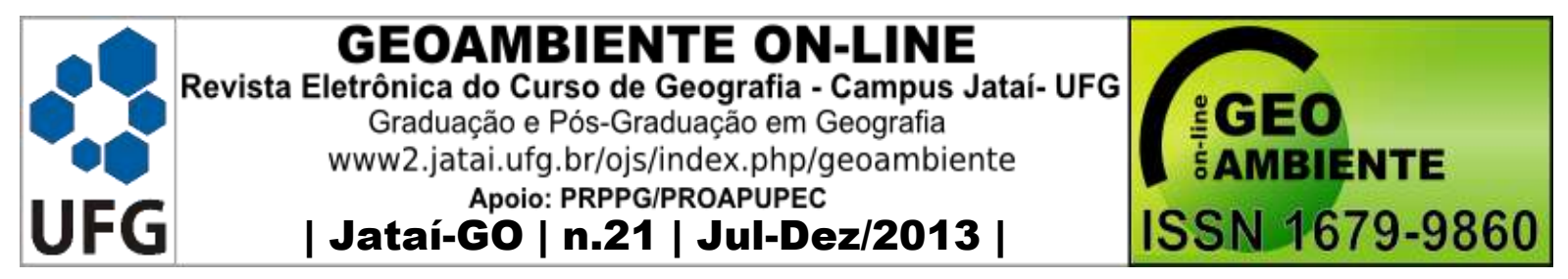

Figura 5: Diagrama do Conforto Humano

DIAGRAMA DO CONFORTO HUMANO

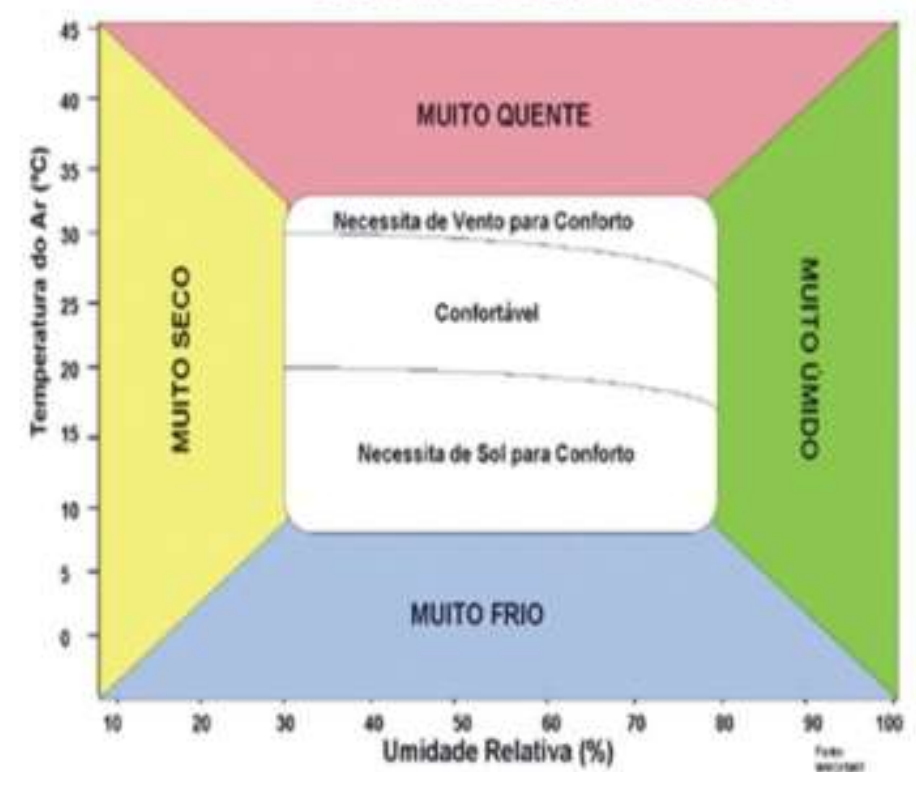

Após a coleta em campo, os dados foram organizados em tabelas e inseridos no software Surfer, que através da ferramenta de interpolação de krigagem ordinária, possibilitou a representação das variações termo-higrométricas em mapas de isolinhas (isotermas e isoígras) (figura 6).

Este procedimento permitiu a visualização das variações de temperatura e umidade relativa do ar, e identificação de áreas com presença de conforto/desconforto térmico. 


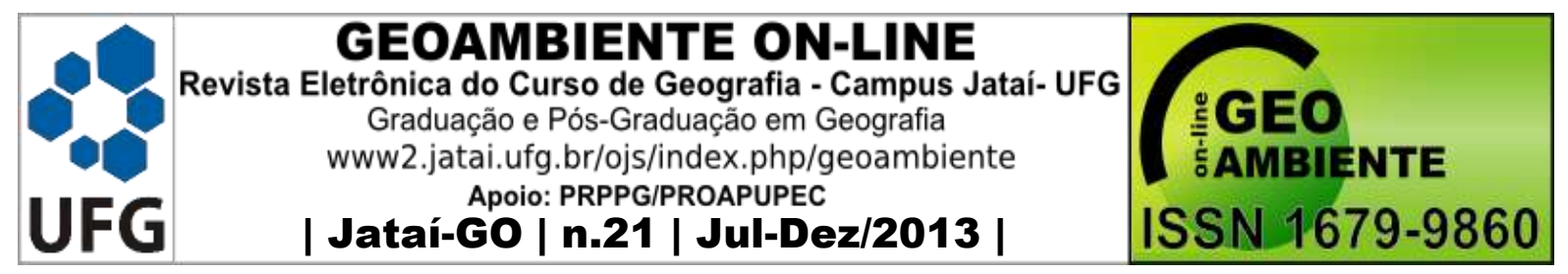

Figura 6: Processo de confecção de mapas de isolinhas no software SURFER.

PROCESSO DE CONFECÇÃO DE MAPAS DE ISOLINHAS NO SOFTWARE SURFER
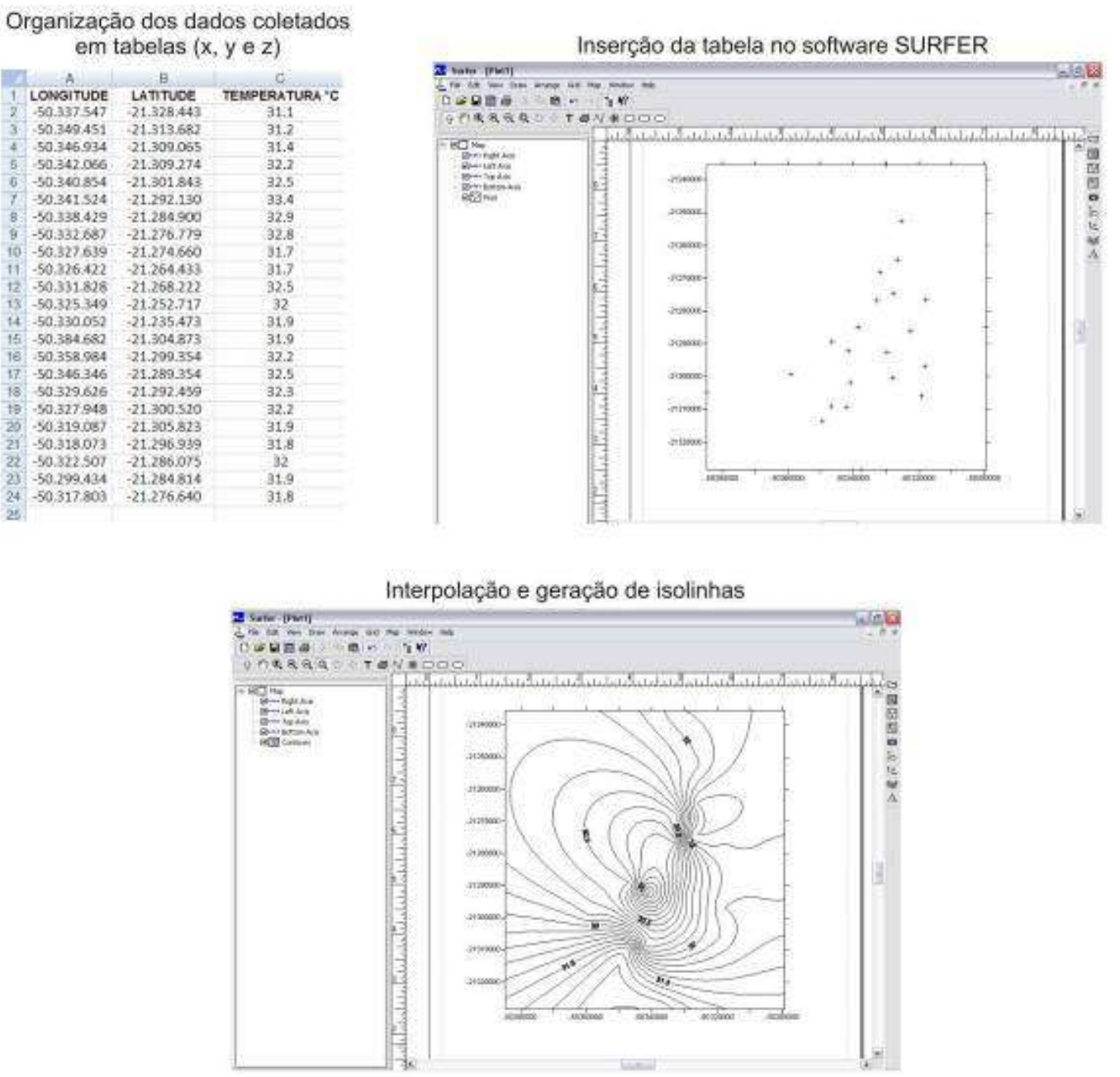

Sobreposiçāo de Isolinhas e Setores Censitários

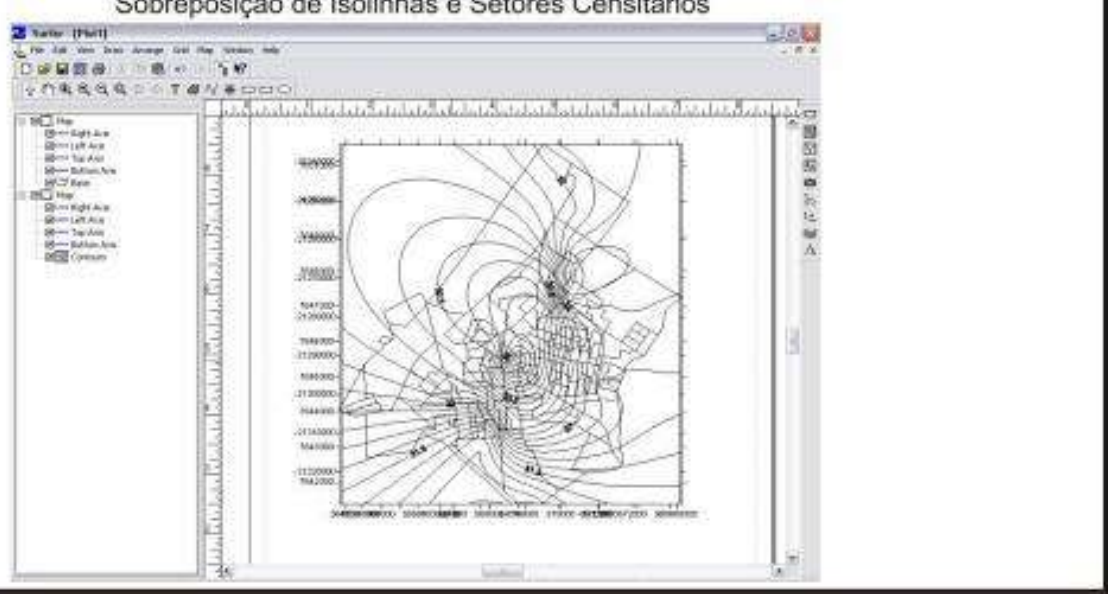




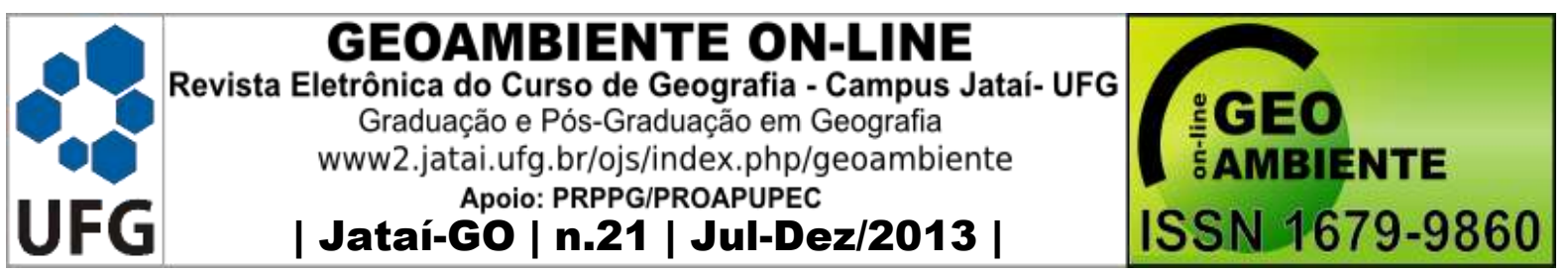

\section{RESULTADOS E DISCUSSÕES}

A região noroeste do Estado de São Paulo, onde está localizado o município de Birigui, possui clima tropical com verões marcados por temperatura elevadas e chuvas freqüentes e invernos secos e com temperaturas amenas. Desta forma, o conforto térmico na região acaba sendo afetado principalmente no verão, devido ao aumento de temperatura e o calor elevado.

As observações foram realizadas durante oito dias da estação de verão, porém no presente trabalho está sendo utilizado como referência o episódio registrado no dia 23/01/2010 (tabela 1).

Tabela 1: Temperatura, Umidade Relativa do Ar e Conforto Humano - 23/01/2010 - Birigui-SP

\begin{tabular}{|c|c|c|c|}
\hline PONTO DE COLETA & TEMPERATURA ${ }^{\circ} \mathrm{C}$ & UR do AR \% & CONFORTO HUMANO \\
\hline Rod. Marechal Rondon & 31.1 & 55 & Necessita de Vento \\
\hline Jd. Vista Alegre & 31.2 & 53 & Necessita de Vento \\
\hline Toselar & 31.4 & 52 & Necessita de Vento \\
\hline Av. Nelson Calixto & 32.2 & 50 & Necessita de Vento \\
\hline Av. Euclides Miragaia & 32.5 & 48 & Muito Quente \\
\hline Centro & 33.4 & 47 & Necessita de Vento \\
\hline Parque do Povo & 32.9 & 46 & Muito Quente \\
\hline Jardim Ipanema & 32.8 & 47 & Muito Quente \\
\hline Pq. das Nações/Jd.Flamengo & 31.7 & 51 & Necessita de Vento \\
\hline Estádio & 31.7 & 50 & Necessita de Vento \\
\hline Recanto Verde & 32.5 & 47 & Muito Quente \\
\hline Rod. Roberto Rolemberg & 32.0 & 49 & Necessita de Vento \\
\hline Portal da Pérola & 31.9 & 51 & Necessita de Vento \\
\hline Colinas & 31.9 & 50 & Necessita de Vento \\
\hline Av. 9 de Julho & 32.2 & 48 & Necessita de Vento \\
\hline Av. João Cernack & 32.5 & 47 & Muito Quente \\
\hline Jd. Klayton & 32.3 & 49 & Necessita de Vento \\
\hline Consolação & 32.2 & 50 & Necessita de Vento \\
\hline Jandaia 2 & 31.9 & 50 & Necessita de Vento \\
\hline CHTMB & 31.8 & 50 & Necessita de Vento \\
\hline Rua Bahia & 32.0 & 49 & Necessita de Vento \\
\hline CHJC & 31.9 & 50 & Necessita de Vento \\
\hline Residencial Quemil & 31.8 & 51 & Necessita de Vento \\
\hline
\end{tabular}

Fonte: Trabalho de Campo - 23/01/2010.

A temperatura apresentou variações consideráveis ao longo da cidade, atingindo um gradiente de $2,3^{\circ} \mathrm{C}$. Observando seu arranjo espacial, nota-se um padrão concêntrico, com as temperaturas mais elevadas na área central e decrescendo suavemente em direção à periferia da cidade. Os registros observados vão de encontro com os resultados de Amorim (2005), que evidenciou em Birigui um perfil térmico com picos positivos de temperaturas nas áreas mais densamente construídas. 


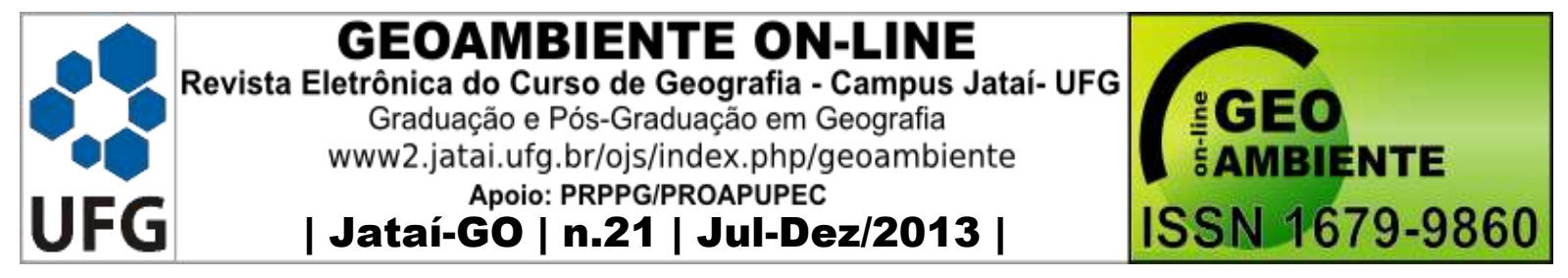

A maior temperatura foi registrada no centro da cidade, no cruzamento entre as ruas Barão do Rio Branco e Nove de Julho $\left(33,4{ }^{\circ} \mathrm{C}\right)$. Trata-se de uma área comercial, com intensa circulação de pessoas e veículos, elevada densidade de construções e altíssimo índice de impermeabilização do solo, além de ser uma das regiões com menor percentual de áreas verde e arborização urbana na cidade.

A região no entorno da área central, como a Avenida João Cernack $\left(32,5 \mathrm{C}^{\circ}\right)$, Avenida Euclides Miragaia $\left(32,5{ }^{\circ} \mathrm{C}\right)$, Parque do Povo $\left(32,9{ }^{\circ} \mathrm{C}\right)$ e Jardim Klayton $\left(32,3{ }^{\circ} \mathrm{C}\right)$, apresentam considerável densidade de edificações e impermeabilização do solo e também registraram temperaturas elevadas quando comparadas com os bairros periféricos.

Observando o mapa de temperatura da área urbana (figura 7), nota-se uma redução dos valores de temperatura em direção a periferia da cidade, é o que ocorre nos bairros Vista Alegre $\left(31,2^{\circ} \mathrm{C}\right.$ e $\left.31,1^{\circ} \mathrm{C}\right)$, Colinas $\left(31,9^{\circ} \mathrm{C}\right)$ e Jandaia II $\left(31,9^{\circ} \mathrm{C}\right)$, onde há baixa densidade de construções; e nos bairros Toselar $\left(31,4^{\circ} \mathrm{C}\right)$, CHTMB $\left(31,8^{\circ} \mathrm{C}\right)$ e João Crevelaro $\left(31,9^{\circ} \mathrm{C}\right)$, com considerável presença de áreas verdes e arborização urbana.

A partir da análise dos resultados, verifica-se que o perfil térmico da cidade aproximase do modelo descrito por Oke (1978) e registrado por Mendonça (2003), em que as temperaturas mais elevadas coincidiram com a área central e mais urbanizadas da cidade (figura 7).

A umidade relativa do ar registrou uma variação de $9 \%$ e uma inversão quanto ao padrão de distribuição espacial em relação à temperatura, sendo os maiores valores registrados nas zonas periféricas e os menores valores ocorrendo na área central da cidade.

$\mathrm{Na}$ área central e entorno a umidade relativa do ar apresentou resultados na faixa de 47\% e 48\% (Parque do Povo, Centro, a Avenida Euclides Miragaia, Avenida João Cernack). Conforme salientado anteriormente, esta é uma área amplamente edificada e impermeabilizada, com pouca cobertura vegetal, o que colabora para baixa umidade do ar.

No entanto, observando a periferia da cidade, especificamente as regiões sul (Toselar, Colinas e Vista Alegre) e leste (Jandaia II, CHTMB, Quemil e João Crevelaro), nota-se a ocorrência de índices de umidade relativa do ar acima de 50\%, ou seja, os maiores valores de umidade relativa do ar coincidiram com os de menor temperatura. Esses bairros são caracterizados pela presença de inúmeros terrenos livres de construção e arborização urbana mais constante do que a área central, tal fato colabora para o maior índice de umidade do ar. 


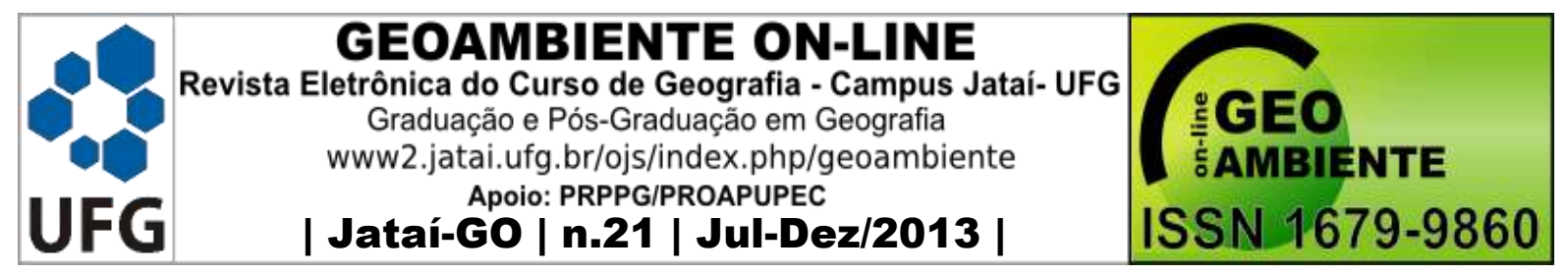

Figura 7: Temperatura do ar - 23/01/2010, Birigui-SP

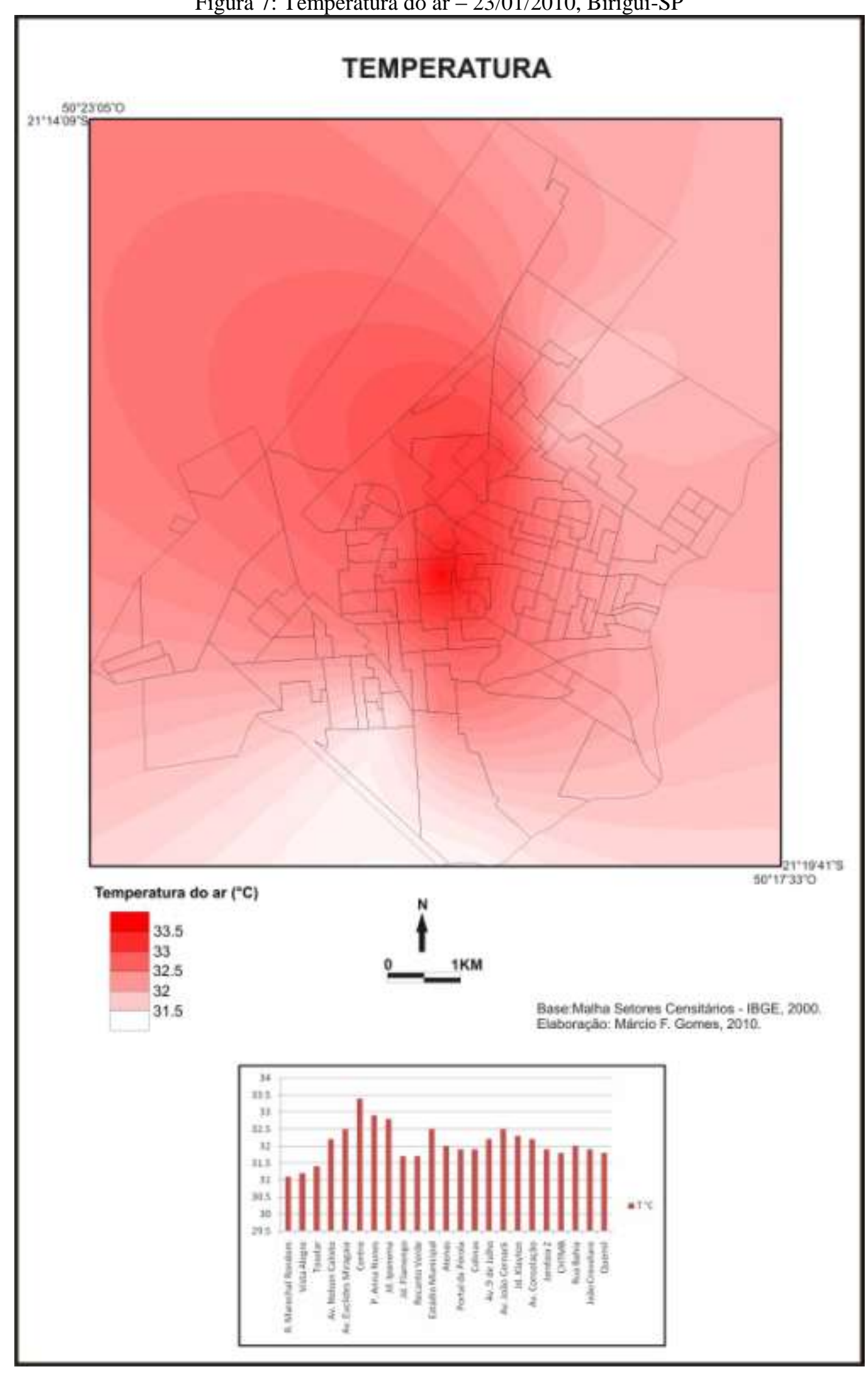

Assim, pode-se afirmar que a umidade relativa do ar apresentou um padrão inverso ao da temperatura, os maiores valores foram registrados nas regiões sul e nordeste da cidade, em 


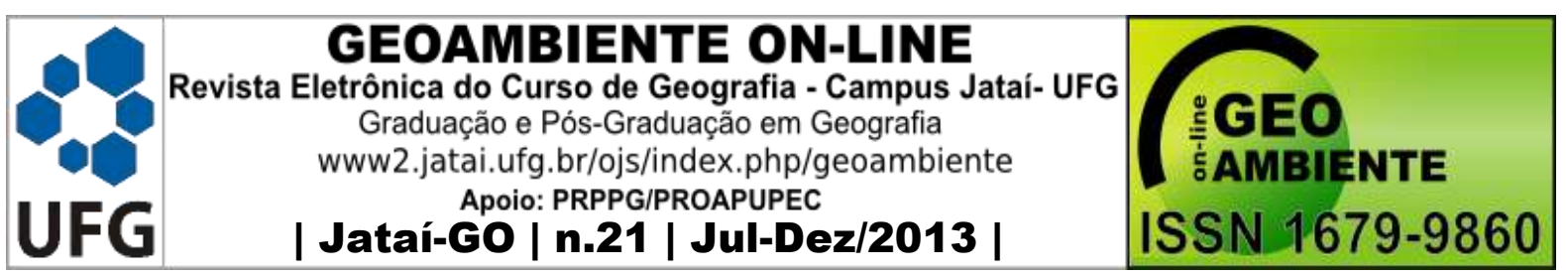

bairros com baixa densidade de edificações e/ou com representativa presença de áreas verdes (figura 8).

Figura 8: Umidade Relativa do $\mathrm{Ar}$ - 23/01/2010, Birigui-SP

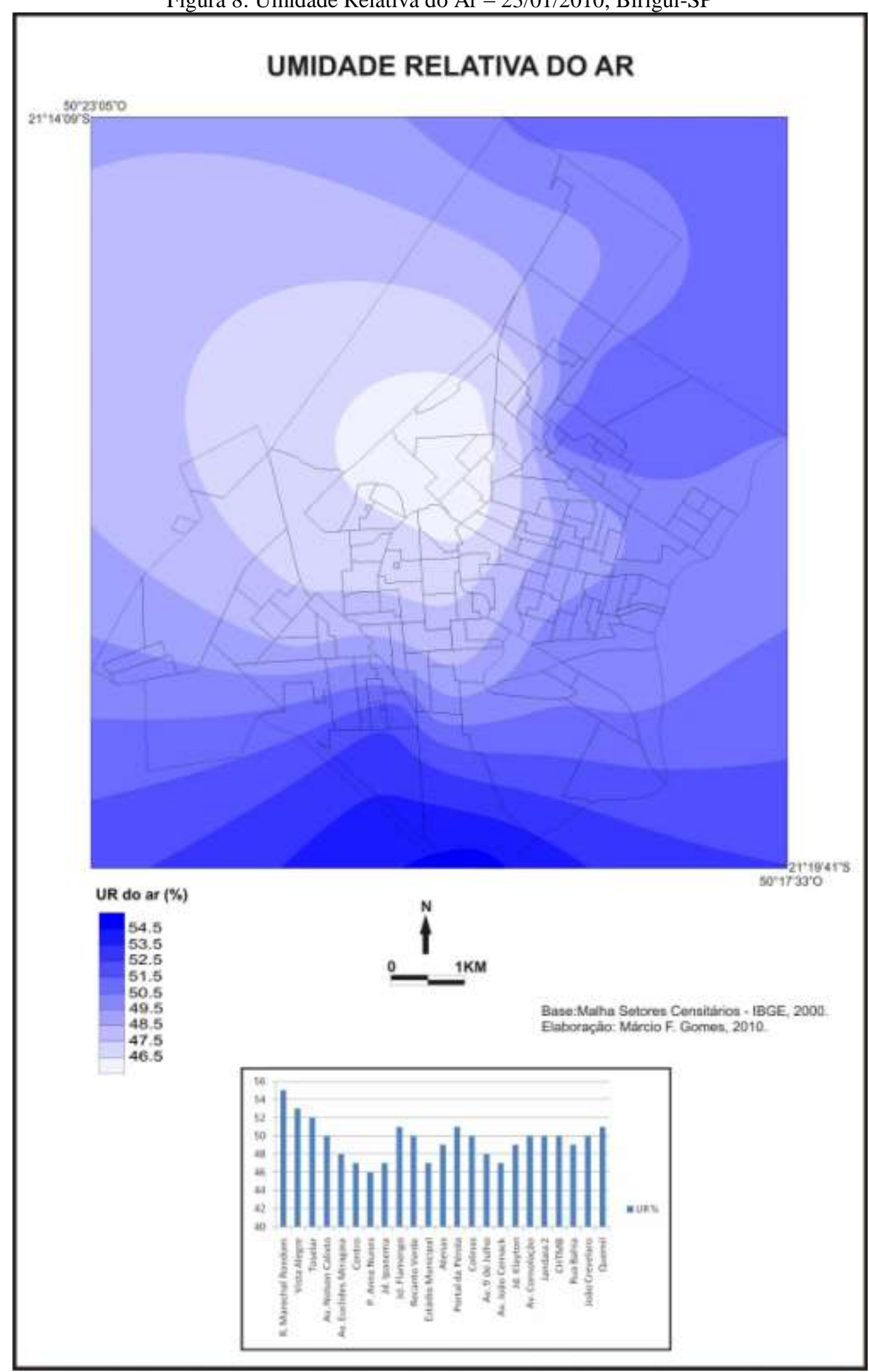




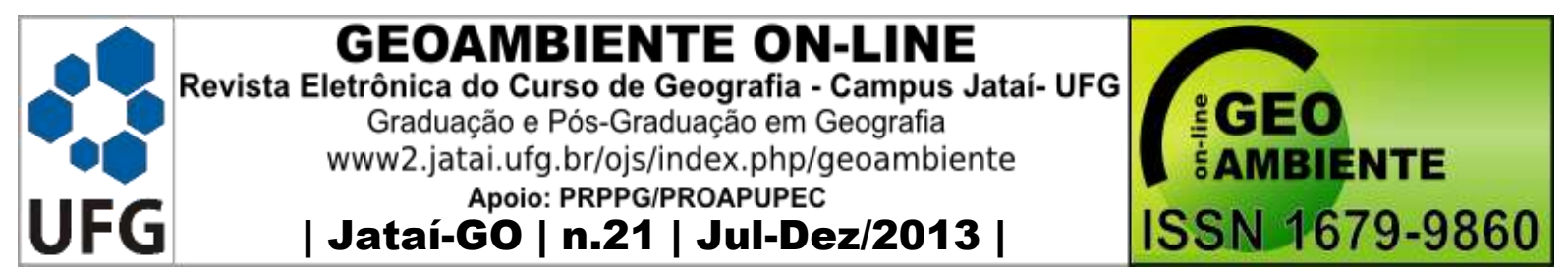

Com base nas condições termo-higrométricas foi avaliado o conforto térmico para a cidade de Birigui, de acordo com o Diagrama do Conforto Humano proposto pelo INMET.

Avaliando-se a cidade como um todo, nota-se que praticamente não há nenhum setor com situação confortável em sua totalidade, ou seja, o município apresenta área urbana caracterizada por desconforto térmico, este fato se dá muito em função da situação explanada anteriormente, onde foram enfatizadas as altas temperaturas da região na estação do verão, agravadas pelas características de uso e ocupação do solo nas áreas urbanas.

Com base no diagrama do INMET, entre os 130 setores censitários urbanos: 23 são considerados muito quentes; 23 estão em uma faixa de transição, sendo parcialmente muito quentes e parcialmente necessitarem de vento para conforto; e 84 necessitam de vento para conforto.

Os resultados registrados na cidade de Birigui refletem um padrão muito comum em diversas cidades brasileiras, com a ocorrência de temperatura elevadas e desconforto térmico na área central, e diminuição da temperatura e do desconforto térmico em direção à periferia (figura 9). 


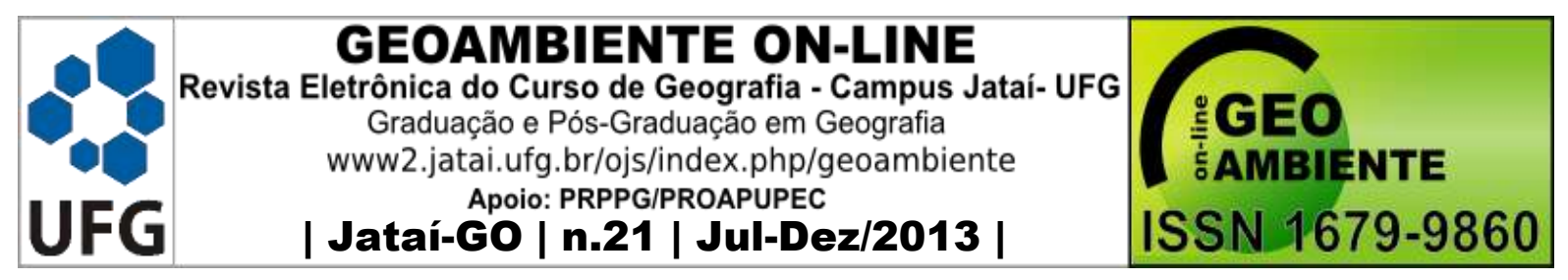

Figura 9: Conforto Térmico - 23/01/2010, Birigui-SP.

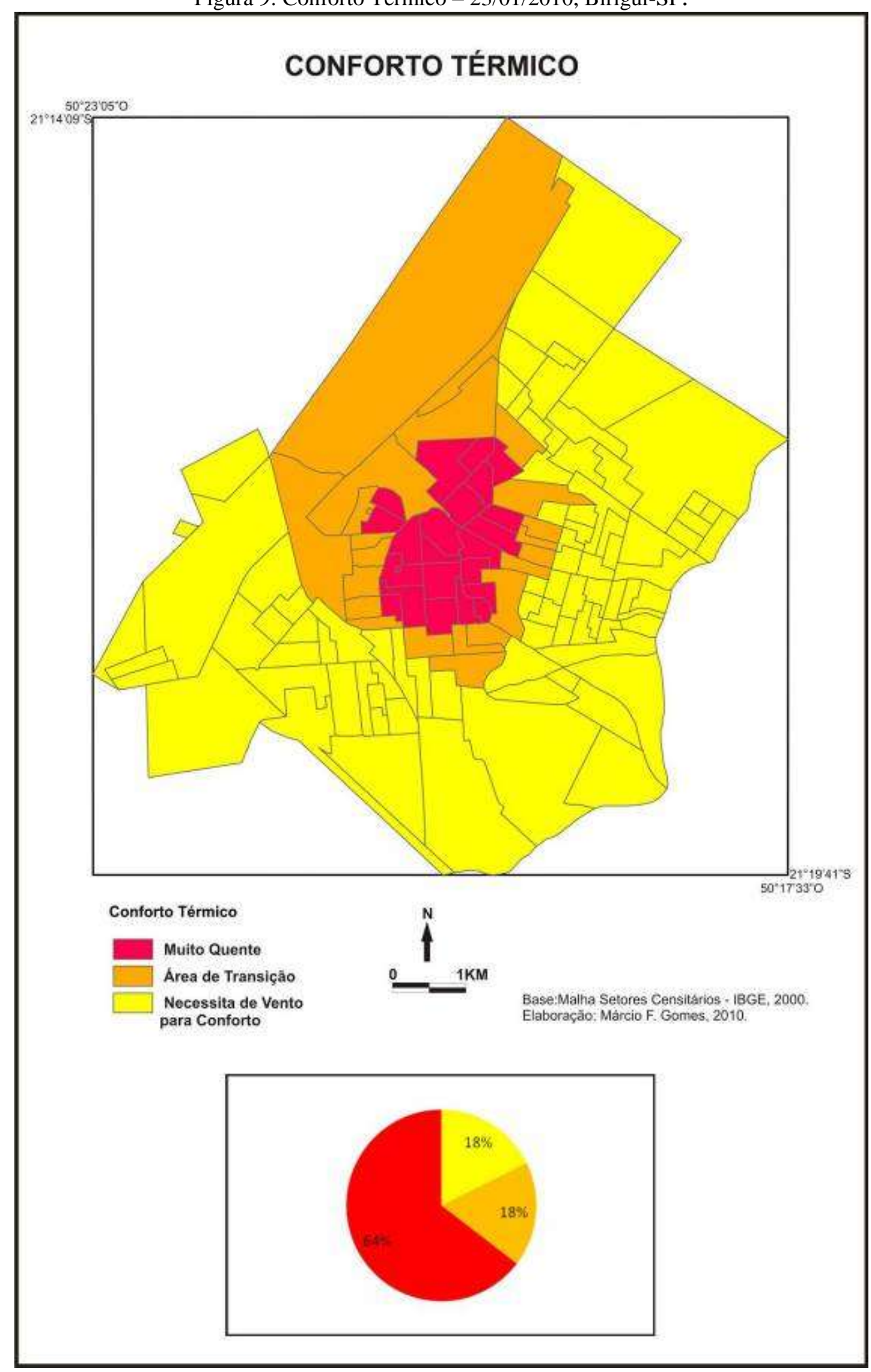




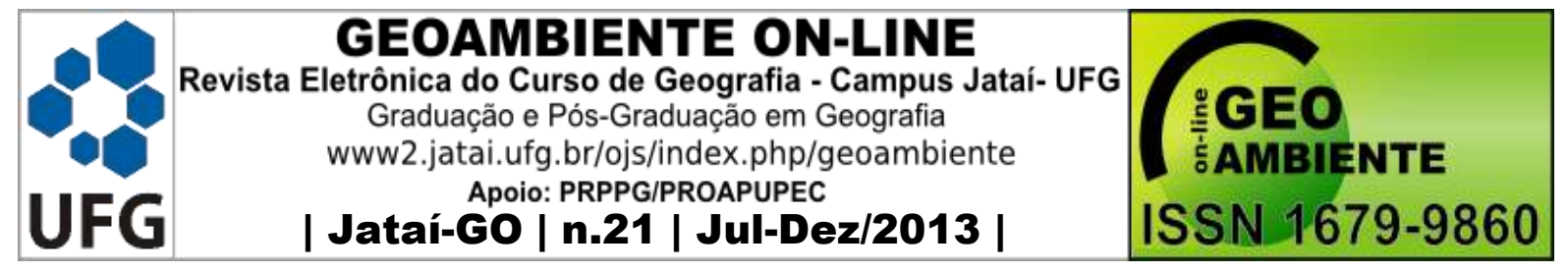

Os resultados evidenciados neste trabalho servem de subsídios para o planejamento ambiental da cidade de Birigui e apontam para as mesmas necessidades salientadas por Mendonça (2003) em Londrina-PR, como: a reordenação de loteamentos, padrão de edificações e concentração de atividade na área central; além da implantação e ampliação de áreas verdes urbanas.

\section{REFERÊNCIAS}

AMORIM, M. C. C. T. O clima urbano de Presidente Prudente. 2000. Tese (Doutorado em Geografia Física) Faculdade de Filosofia, Letras e Ciências Humana, Universidade de São Paulo, São Paulo.

AMORIM, M. C. C. T. Ilhas de Calor em Birigui/SP. Revista Brasileira de Climatologia, Vol. $1, \mathrm{~N}^{\circ} 1,2005$.

BESANCENOT, J. P. Le climat et la santé. France; Presses Universitaires de Rennes, 1997.

DUMKE, E. M. S. Clima urbano/conforto térmico e condições de vida na cidade - uma perspectiva a partir do Aglomerado Urbano da Região Metropolitana de Curitiba (AU$R M C$.) Curitba, 2007. Tese (Doutorado em Meio Ambiente e Desenvolvimento) Universidade Federal do Paraná-UFPR, Curitiba, 2007.

ERIKSEN, W. Klimatologisch - Ökologische Crapekte des Umweltbelastung Hannovers Stadklima und Lutverunreinigung. In: Hannover ond sein Unland. Hannover, 1978

GARCIA, C. M. Climatologia Urbana. Barcelona: Universidade de Barcelona, 1999.

GARCIA, F. F. Manual de climatologia, medio ambiente y planificación. Madrid: Editorial Sintesis, 1996

GOMES, M. F. A cartografia temática como instrumento de análise e síntese no estudo da qualidade de vida urbana: O caso da cidade de Birigui:SP. 2011. 217 f. Dissertação (Mestrado em Geografia). Programa de Pós-Graduação em Geografia, Universidade Estadual de Maringá, Maringá, 2011.

IBGE. Censo Demográfico 2000. <Disponível em: http://www.ibge.gov.br/home/download/estatistica.shtm > Acesso em 10 de janeiro de 2010. KOPPEN, W. P. Clima. In. Enciclopédia Mirador Internacional. São Paulo: Enciclopédia Britânica do Brasil, 1995. 


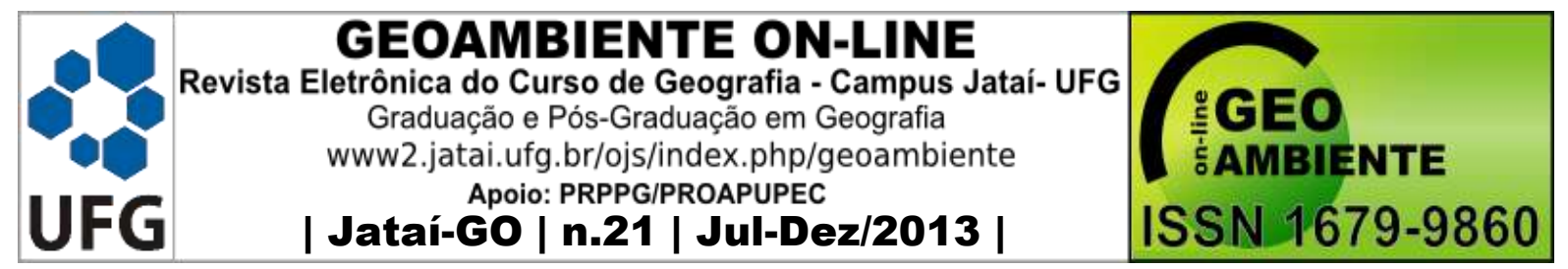

KRÜGER, E. Conforto Térmico: a necessidade de adaptação climática como forma de sobrevivência. Cadernos Técnicos - AUT/Universidade de São Paulo, São Paulo, n. 10, p. 23 $38,2002$.

LOMBARDO, Magda A. Ilha de Calor nas Metrópoles - o exemplo de São Paulo. São Paulo: HUCITEC, 1985. 244p.

MENDONÇA, F. A. O clima urbano de cidades de porte médio e pequeno: aspectos teóricometodológicos e estudo de caso. In: SANT’ANNA NETO, J. L.; ZAVATINI, J.A. (Org.) VARIABILIDADE E MUDANÇAS CLIMÁTICAS: Implicações ambientais e socioeconômicas. Maringá: EDUEM, p.167 - 192, 2000.

MENDONÇA, F. A. Clima e criminalidade: ensaio analítico da correlação entre a temperatura do ar e a incidência da criminalidade urbana. Curitiba: Editora da UFPR, 2001. $182 \mathrm{p}$.

MENDONÇA, F. CLIMA E PALENJAMENTO URBANO EM LONDRINA: Proposições metodológicas e de investigação urbana a partir do estudo do campo termo-higrométrico. In: MONTEIRO, C. A. F.; MENDONÇA, F. (Org.) Clima Urbano. São Paulo: Contexto, 2003, p. $93-120$.

MONTEIRO, C.A.de F. Qualidade ambiental - Recôncavo e Regiões limítrofes. Salvador, Centro de Estatísticas e Informações, 1987, 48p e 3 cartas

OKE, Tim R. Boundary layer climates. London: Methuen, 1978. 372 p.

PITTON, S. E. C. As cidades como indicadoras de alterações térmicas. 1997. 272p. Tese (Doutorado em Geografia Física) - Faculdade de Filosofia, Letras e Ciências Humana, Universidade de São Paulo, São Paulo.

RIBEIRO, H.; SILVA, E. N. Alterações da temperatura em ambientes externos de favela e desconforto térmico. Revista de Saúde Pública, v. 40, n. 4, p. 663 - 670, 2006.

RORIZ, Maurício. Zona de conforto térmico: um estudo comparativo de diferentes abordagens. Dissertação (Mestrado em Arquitetura). Departamento de Arquitetura e Planejamento, Universidade de São Paulo. São Carlos, 1987.

TROPPMAIR, H. Biogeografia e Meio Ambiente. Rio Claro, 1987.

TARIFA, J. R. Análise comparativa de temperatura e umidade na área urbana e rural de são José dos Campos-SP-Brasil. Geografia, 2(4), p.59-80, 1977. 


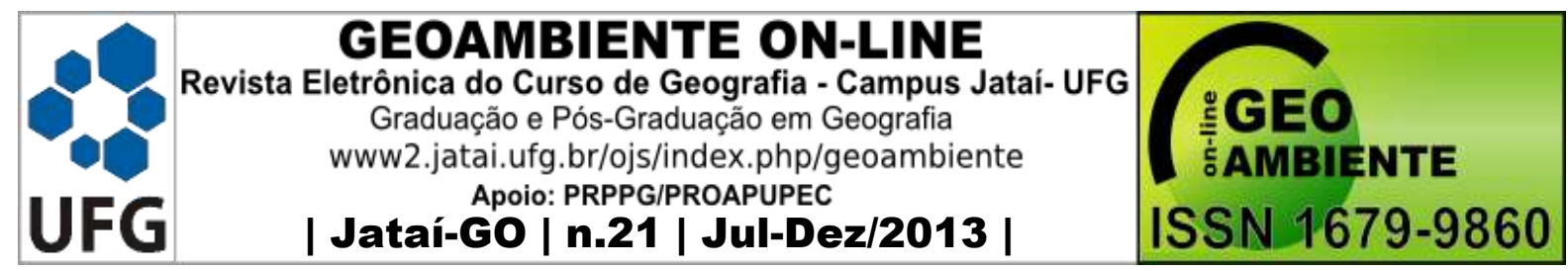

VOGT, J. J.; MILLER-CHAGAS, P. Confort thermohygrométrique - Definition physiologique et determination pratique de zones de confort thermique. Équipement Technique 85, n. 271-272, p. 143-54, Jullet-About, 1970. 